\title{
Powering the wireless world with MEMS
}

\section{Samuel Schaevitz}

Samuel B. Schaevitz, "Powering the wireless world with MEMS," Proc. SPIE 8248, Micromachining and Microfabrication Process Technology XVII, 824802 (2 February 2012); doi: 10.1117/12.924356

SPIE. Event: SPIE MOEMS-MEMS, 2012, San Francisco, California, United States 


\title{
Powering the Wireless World with MEMS
}

\author{
Samuel B. Schaevitz* \\ Lilliputian Systems, Inc. \\ 36 Jonspin Rd, Wilmington, MA, USA 01887 \\ sams@LSInc.biz
}

\begin{abstract}
Battery life is huge problem for today's CE devices and every year the problem gets worse. That is a painful consequence of the explosion in capability and applications in modern wireless electronics of all types, and is particularly acute in advanced smartphones. Fuel cells have long been touted as the solution to the battery problem, and significant programs have been funded at large companies, start-ups, and within academia. Thus far, none of those efforts have resulted in a commercially successful product for consumer electronics.

Lilliputian Systems has taken a unique approach by leveraging MEMS fabrication methods to enable the use of a fuel cell known as a solid oxide fuel cell (SOFC). SOFCs provide high efficiency and reliable operation in a very compact Silicon Power Cell ${ }^{T M}$, and allow the use of high energy density fuels, such as butane. This combination overcomes the barriers which have prevented other fuel cell efforts from being commercialized. But in order to use SOFCs, the MEMS structure must operate at elevated temperatures, typically above $600^{\circ} \mathrm{C}$, must do so very efficiently, and must be effectively integrated into a complete system. By overcoming these unusual challenges, Lilliputian has developed a solution with a run-time 5-10X longer than existing batteries and with instant recharge by inserting a new cartridge. The absolute safety of the approach is supported by world-wide approval for carry-on and use on airplanes.

Over the past several years, Lilliputian Systems has created the many innovations required to bring this complex system to high-volume manufacturing. We will discuss the unique challenges in system architecture and high-temperature MEMS design which have been overcome, enabling Lilliputian to provide long-lasting portable power for consumer electronics devices.
\end{abstract}

Keywords: Portable Power, USB, Smartphone, Fuel Cell, SOFC, Butane, MEMS, Glass Seal, Simulation, System

\section{INTRODUCTION}

Modern consumer electronics boast an impressive range of capabilities, with the ability to wirelessly accomplish almost anything imaginable, but they suffer from a painful Achilles heel of inadequate batteries. On-the-go users are often tied to a wall plug for hours to recharge their devices. Fuel cells have long held out the promise of cutting that final cord, but have thus far fallen short of delivering a compelling power source for consumer electronics devices. We have combined a diverse range of MEMS and materials developments to extract the most possible value from the fuel cell promise. Lilliputian Systems has chosen the highest energy density fuels, combined with the most efficient and dependable fuel cells, in a MEMS-enabled very compact form factor, in order to deliver a product which can power the latest smartphones for weeks.

High-energy butane fuel and high-efficiency solid oxide fuel cells (SOFCs) both require operating at temperatures above $600^{\circ} \mathrm{C}$. Lilliputian leverages microfabrication techniques to solve the challenges of extreme insulation, high-temperature multi-chip sealing, severe thermal expansion stresses, compact electrical routing, and optimal distributions for the coupled flow, electrical and chemical reactions. These microfabricated and packaged technologies are then integrated into a complete system in order to deliver a powerful user experience.

\subsection{Portable Power Market}

Recent trends in the Consumer Electronics (CE) market have resulted in increased energy requirements for billions of portable devices. Moreover, the increase is both rapid and accelerating due to four unique trends.

First, CE devices today are equipped with faster and more power consumptive processors than previously available, they exhibit increased network connectivity rates and antenna power requirements, and often have larger, brighter and more

Micromachining and Microfabrication Process Technology XVII, edited by Mary Ann Maher, Paul J. Resnick, Proc. of SPIE Vol. 8248, 824802 - (C) 2012 SPIE · CCC code: 0277-786X/12/\$18 · doi: 10.1117/12.924356 


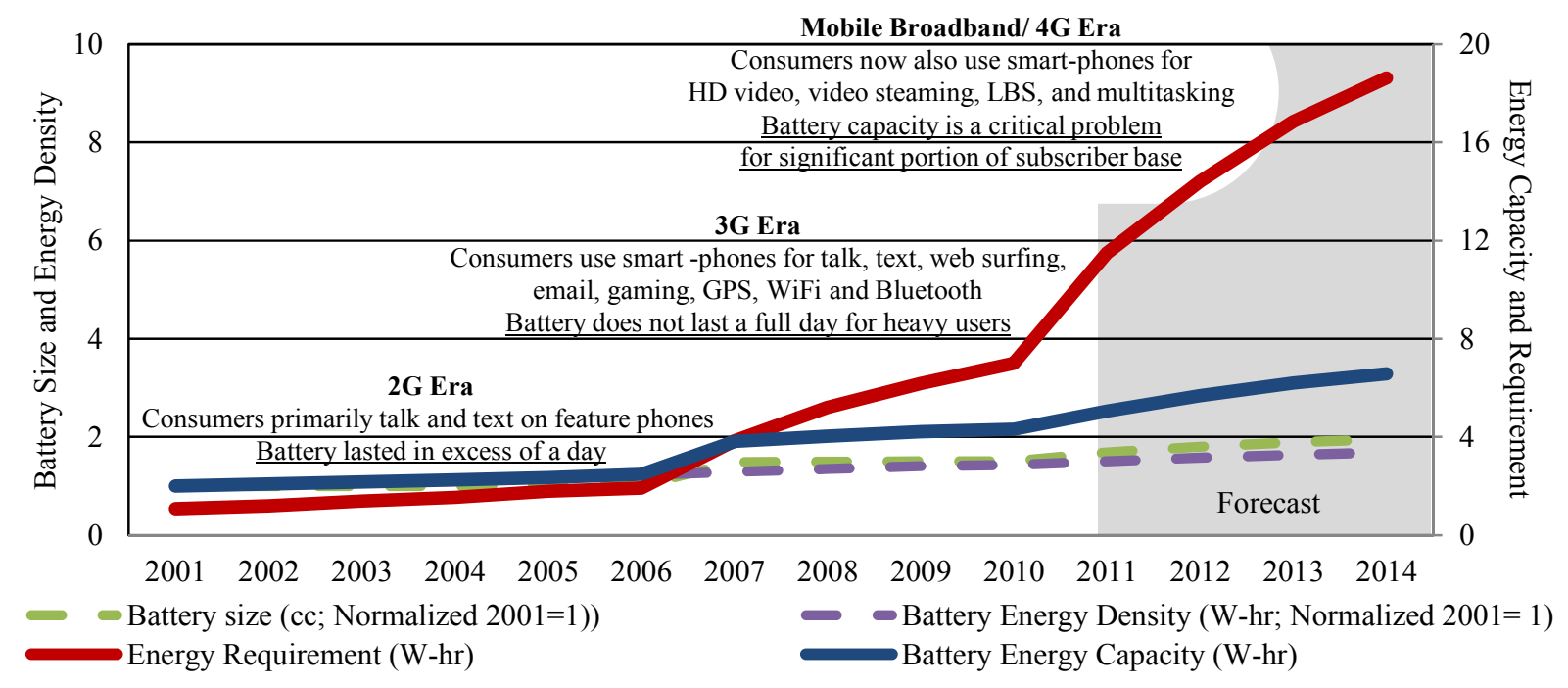

Figure 1: Energy needs and capacities of cellphones vs. time.

power hungry displays (e.g. touch-screens) than models of even a just few years ago. Smartphones are an obvious illustration of this trend, but this phenomenon is by no means exclusive to them or similar communications devices. Digital cameras, mp3 players, tablets, GPS devices, Bluetooth devices and an array of new and innovative consumer electronics products all exhibit both this and the following trends. Consequently, we are witnessing a fundamental increase in the intrinsic power requirements of $\mathrm{CE}$ devices themselves.

A second market trend is the growing consumer preference to use CE devices in a mobile environment, specifically away from a wall outlet. Through the sales of mobile phones and tablets, consumers have clearly communicated their desire for an untethered experience (e.g. mobile gaming, web surfing "on-the-go", remote access to databases or cloudbased services) with their CE devices. InformationWeek conducted a survey in 2008 in which they found that over $37 \%$ of business professionals occasionally or frequently left their laptops at home in favor of using their smart phones for their business needs ${ }^{[1]}$ Lack of access to the wall outlet naturally leads to a greater dependence on the CE battery itself.

A third trend that we observe is the higher sophistication and greater number of features and applications on the devices themselves. Again smartphones can serve to illustrate this point. In the not too distant past, mobile phones were primarily used for phone calls and, to a lesser extent, for sending short text messages. Now multifunction smartphones provide high quality real time web/ data access and synchronization, broadcast and high definition video, an array of applications that heavily tax either the antenna system or processor power (or both), and an increasing list of location based services (e.g. targeted advertising, GPS, and traffic services). All of these features and applications have imposed greater power and energy demands on the CE device battery.

How likely would you be to purchase the product if each cartridge had enough power to charge your devices for:

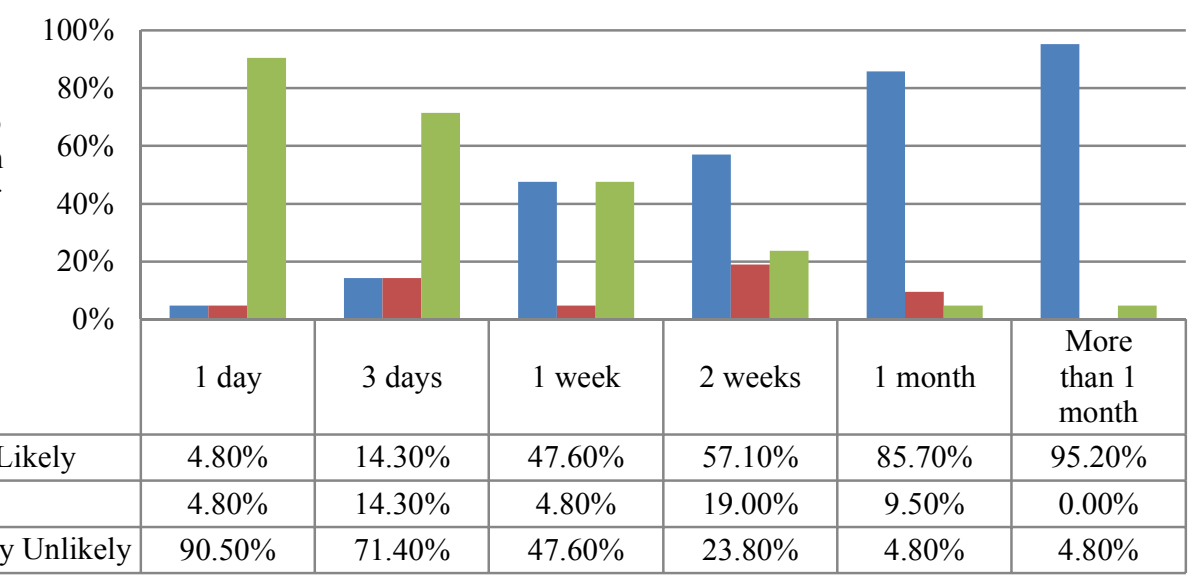

Figure 2: Consumers demand 1 week or more. 
What is the Maximum Price you would pay for this product?

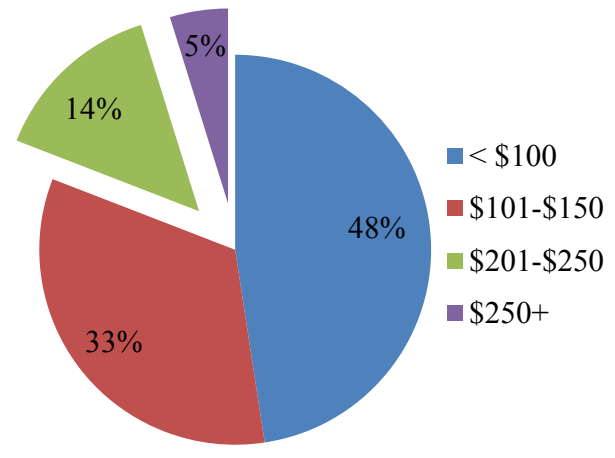

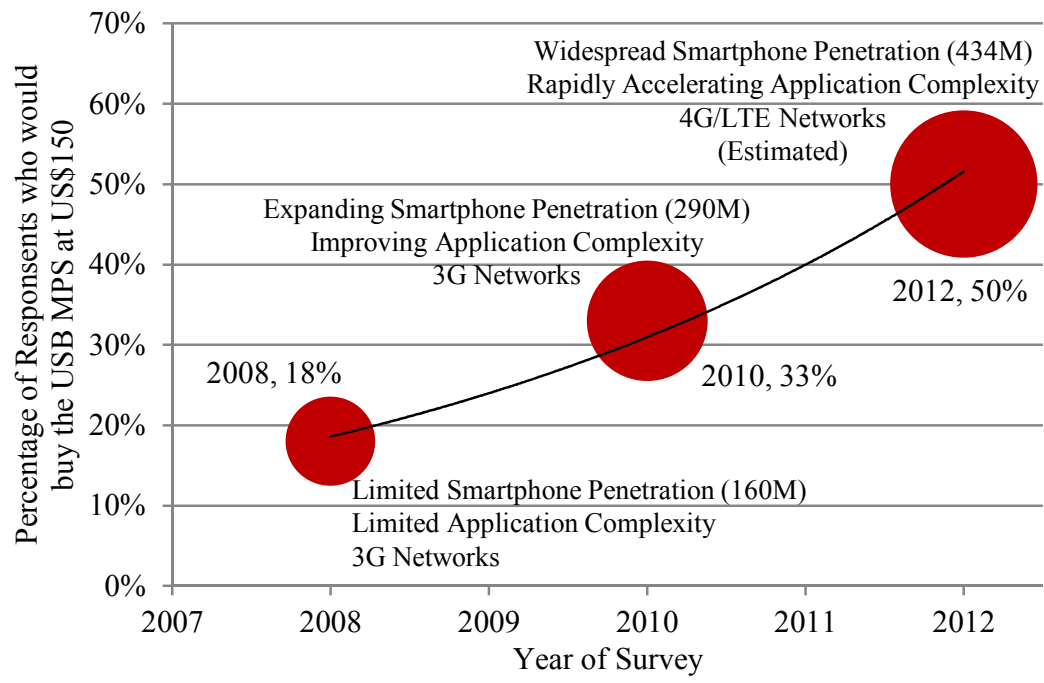

Figure 3: Price sensitivity results showing consumers are increasingly prepared to pay for portable power.

The final trend, partly a consequence of those enumerated above, is the increased dependence and reliance upon the $\mathrm{CE}$ device for daily use. We observe soaring usage rates in an "always-on, always-connected" society. In many ways, the mobile phone has become a lifeline to the user, nearly as important as wallets (and in some societies, having replaced wallets entirely!).

Thus as CE devices (i) have become more power consumptive, (ii) are increasingly used away from stationary power sources, (iii) are equipped with more numerous, more power hungry features and applications, and (iv) are being used more frequently, it stands to reason that that the demands placed on the internal battery will have also increased enormously. Several studies have confirmed this fact. Detailed analyses by Parks Associates ${ }^{[2]}$ and Strategy Analytics $^{[3],[4],[5]}$, among many other publicly-available and company-confidential studies, have attempted to quantify this increase in demand. One such study, published by Cisco, estimates that US mobile data traffic will grow at an astonishing $92 \%$ annually, and by 2015 will result in over 6.3 exobits of data traversing the network each month ${ }^{[6]}$. Unfortunately much of the same research shows that improvements in battery technology (whether Lithium Ion, Lithium Polymer or new technologies) are simply not able to address the higher demands imposed by the CE devices.

In a detailed study conducted by Lilliputian, we found that energy density in mobile device battery technology has improved by slightly over $5 \%$ per year since 2001 . Shown in Figure 1, on average, physical battery sizes themselves have grown slightly - usually in tandem with the advent of a new mobile standard (e.g. $2 \mathrm{G}$ and $3 \mathrm{G}$ ) or a new class of devices (e.g. Apple's iPhone). However, these improvements are insufficient when compared with a consumer demand that has grown tenfold. Lilliputian measured the net energy density and physical sizes of scores of batteries of both smartphones and feature-phones that were commonly available in the United States marketplace in the 2001 to 2011 timeframe. These ranged from many original $2 \mathrm{G}$ devices, such as the early iPhones, Motorola RAZR, Palm Treo and Blackberry Curve, to several high end $3 \mathrm{G}$ and $4 \mathrm{G}$ phones, including the later iPhone, HTC Incredible/ Thunderbolt, Samsung Infuse and Motorola Droid product lines. The measurements resulted in a net energy capacity (in Watt-hours) of the battery that Lilliputian represented in a dark blue line in Figure 1. Lilliputian also analyzed the "per-feature" consumer usage patterns of the phones during the same time period and was able to show the energy demands placed on the battery by each of those usage patterns. For instance, early $2 \mathrm{G}$ phones were used primarily for features such as talking and texting. This resulted in a relatively low energy demand on batteries of that era. Conversely, today's phones are used for a number of higher energy-intensive features and applications including WiFi, GPS location-based services, video streaming, gaming, continuous cloud synchronization, and multi-tasking. The combination of the "per-feature" consumer usage pattern and the energy requirements per feature were calculated and are represented by the dark red line in Figure 1. The results of the analysis clearly show the large and growing energy demand gap of a heavy user's daily mobile phone requirement. In layman's terms, this is the fundamental reason that most users cannot accommodate a full day of mobile device use without hunting for a plug and recharging the device mid-day. Note that as more advanced LTE, 4G and HSPA/ HSPA+ networks are deployed with increasing frequency throughout the globe, the analysis further predicts a doubling of their daily demand by 2014. Batteries are simply unable to meet this growing energy demand. 

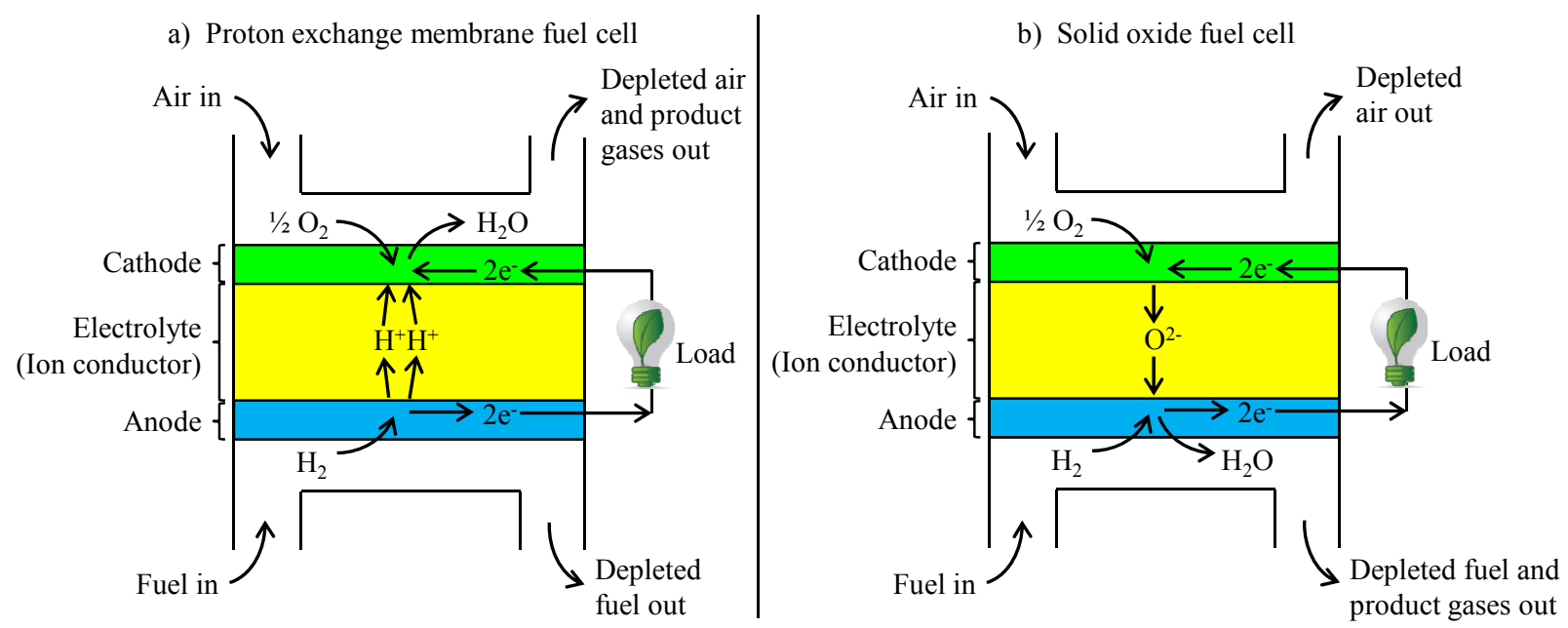

Figure 4: Operating principles of the most common portable fuel cells.

In their November 2009 study, Parks Associates conducted a detailed analysis and published "Mobile Convergence: Platform, Applications \& Services - 3Q 2009." ${ }^{\text {[2] }}$ Section VII focused on "Phone Battery Life, Charging and Refueling" in which they proposed a hypothetical fuel cell charger where the user could conveniently and inexpensively purchase "fuel." "Refueling" of the hypothesized device would be quick and available at retail. Parks Associates' concluded: "The proposed fuel cell charger product appeals to a large crowd of consumers. Up to $60 \%$ of mobile consumers are interested and willing to buy the proposed fuel cell charger ..." and "High spenders reported likelihood to use more mobile communication and entertainment." The survey also found that $42 \%$ of power consumers wanted one week to one month of power per "refill." Equally importantly to wireless carriers, as they move towards a "pay per GB" model for data services, the increase in power results in an increase in usage of data services, and by extension and increase in their company profits.

Lilliputian has conducted a number of surveys and focus groups which correlate strongly with Parks' conclusions. An excerpt from a detailed study conducted with a partner organization (Figure 2) shows that when a hypothesized product cartridge provides one week or more of power, nearly half of the consumer base is "likely" or "very likely" to purchase such a product. Moreover, Lilliputian also confirmed that when such cartridges were available, a significant portion of the target demographic of the survey base - approximately $50 \%$ - was prepared to pay US\$100 or more for the device (Figure 3).

Notably, all of Lilliputian's research suggests that a portable power product would solve a key need for heavy users of smart phones, and that usage of the product increases when travelling or when the user is away from a plug for extended periods of time. Furthermore, over time there is a clear correlation between increased desirability of the product and an increase in the portable power problem faced by consumers (Figure 3). Hence it is evident that the market trends are leading portable $\mathrm{CE}$ devices to require greater levels of power, and consumers are clamoring for better power and energy solutions for these devices. Battery technology has been unable to meet these demands, and as these trends and requirements continue to grow, so does the need.

\subsection{Fuel Cell Alternatives}

The need for better solutions to power portable electronics has been apparent for decades ${ }^{[7]}$, with a heavy focus on fuelpowered systems. Fuel powered systems have a fundamental advantage over a battery due to the use of "free" ambient air. The system needs only carry the relatively small weight of the fuel to leverage that free resource. The incumbent, batteries, have the advantage of being self-contained, but in return, they are obligated to include both anode and cathode. This results in a weight and volume disparity of up to $100 \mathrm{x}$ between the fundamental energies carried by the chemistry in each system. However, fuel-based systems suffer from two significant drawbacks. First, the fuel is converted into electricity at relatively low efficiencies compared to batteries. Second, the system itself takes up a majority of the volume in portable applications, so that there is a limited available space for the fuel itself. Those drawbacks are a steep challenge, and frequently overwhelm the initial energy advantage. 
Table 1: Common fuel cell system types for portable applications.

Note: Fuel energy ranges are based on commonly used fuel dilutions.

\begin{tabular}{|c|c|c|c|c|c|}
\hline Fuel Cell System Type & $\begin{array}{l}\text { Mobile } \\
\text { Ion }\end{array}$ & $\begin{array}{l}\text { Electrolyte } \\
\text { Material }\end{array}$ & $\begin{array}{c}\text { Fuel } \\
\text { Chemical Energy }\end{array}$ & $\begin{array}{c}\text { Typical } \\
\text { Operating } \\
\text { Temperature }\end{array}$ & System Description \\
\hline $\begin{array}{l}\text { PEM } \\
\text { (Proton Exchange Membrane) } \\
\text { Using Metal Hydride } \\
\text { Canisters }\end{array}$ & $\mathrm{H}^{+}$ & $\begin{array}{l}\text { Hydrated } \\
\text { Polymer }\end{array}$ & $\begin{array}{l}\text { Hydrogen in } \\
\text { Metal Hydride } \\
1,000-3,000 \\
\text { W-Hr/L Fuel }\end{array}$ & $0-200{ }^{\circ} \mathrm{C}$ & $\begin{array}{l}\text { The fuel cell uses hydrogen released } \\
\text { from the metal hydride }\end{array}$ \\
\hline $\begin{array}{l}\text { PEM } \\
\text { (Proton Exchange Membrane) } \\
\text { Using Borohydride Fuel }\end{array}$ & $\mathrm{H}^{+}$ & $\begin{array}{l}\text { Hydrated } \\
\text { Polymer }\end{array}$ & $\begin{array}{c}\text { Sodium } \\
\text { Borohydride } \\
2,000-7,000 \\
\text { W-Hr/L Fuel }\end{array}$ & $0-200{ }^{\circ} \mathrm{C}$ & $\begin{array}{l}\text { The fuel cell uses hydrogen produced } \\
\text { within the system from the reaction of } \\
\text { the borohydride with water }\end{array}$ \\
\hline $\begin{array}{l}\text { DMFC } \\
\text { (Direct Methanol Fuel Cell) } \\
\text { (Variant on a PEM) }\end{array}$ & $\mathrm{H}^{+}$ & $\begin{array}{l}\text { Hydrated } \\
\text { Polymer }\end{array}$ & $\begin{array}{c}\text { Methanol } \\
3,000-5,000 \\
\text { W-Hr/L Fuel }\end{array}$ & $0-80^{\circ} \mathrm{C}$ & $\begin{array}{l}\text { Similar in construction to PEM, with } \\
\text { a methanol solution provided directly } \\
\text { as a fuel }\end{array}$ \\
\hline $\begin{array}{l}\text { IDMFC } \\
\text { (Indirect Methanol Fuel Cell) } \\
\text { (Variant on a PEM) }\end{array}$ & $\mathrm{H}^{+}$ & $\begin{array}{l}\text { Hydrated } \\
\text { Polymer }\end{array}$ & $\begin{array}{c}\text { Methanol } \\
3,000-4,400 \\
\text { W-Hr/L Fuel }\end{array}$ & $\begin{array}{c}0-80{ }^{\circ} \mathrm{C}(\mathrm{FC}) \\
250-400{ }^{\circ} \mathrm{C} \\
\text { (Reformer) }\end{array}$ & $\begin{array}{l}\text { The fuel cell uses hydrogen which is } \\
\text { generated within the system by } \\
\text { reforming methanol }\end{array}$ \\
\hline $\begin{array}{l}\text { FAFC } \\
\text { (Formic Acid Fuel Cell) }\end{array}$ & $\mathrm{H}^{+}$ & $\begin{array}{l}\text { Hydrated } \\
\text { Polymer }\end{array}$ & $\begin{array}{c}\text { Formic Acid } \\
1,500-2,000 \\
\text { W-Hr/L Fuel }\end{array}$ & $0-80^{\circ} \mathrm{C}$ & $\begin{array}{l}\text { Similar in construction to PEM, with } \\
\text { a Formic Acid solution provided as } \\
\text { fuel }\end{array}$ \\
\hline $\begin{array}{l}\text { SOFC } \\
\text { (Solid Oxide Fuel Cell) }\end{array}$ & $\mathrm{O}^{2-}$ & Ceramic & $\begin{array}{c}\text { Various } \\
\text { Hydrocarbons } \\
7,000-8,000 \\
\text { W-Hr/L Fuel }\end{array}$ & $500-1000{ }^{\circ} \mathrm{C}$ & $\begin{array}{l}\text { The fuel cell either uses hydrocarbon } \\
\text { fuel directly or the fuel is first } \\
\text { reformed to hydrogen and carbon } \\
\text { monoxide within the system }\end{array}$ \\
\hline
\end{tabular}

Fuel cells are the most promising approach to deliver on the promise of fuel-powered portable electronics. William Grove is credited with inventing the first fuel cell in 1839, and there have been a plethora of variants developed in the subsequent years. Types of fuel cells are differentiated by their different fuels and/or different electrolytes with associated mobile ions (Figure 4). All variants have the same basic operating principle: a fuel cell is an electrochemical device, like a battery, but where oxygen gas provides the cathodic potential. Typically the anode is also provided with a continuous supply of fuel. Fuel cells seem to be the most promising fuel-based systems available for small, portable devices because they typically produce relatively high efficiencies and can be relatively simple and small systems.

The potential application of fuel cells to the large consumer market has spawned development activities in at least 50 companies, and untold academic efforts. Each group has pursued a slightly different technical approach, but almost all current and recent efforts fall into one of the categories listed in Table 1. (These categories were selected from the recently issued International Electrotechnical Commission (IEC) specification for Portable Fuel Cells ${ }^{[8]}$.) Each of these fuel cell systems were chosen by their proponents because they have advantages in efficiency or simplicity, in order to maximize the energy delivered from the complete system.

However, being efficient, simple, and small enough to beat a battery has proven to be difficult. Only a small number of fuel cell products aimed at consumer electronics have reached the general public, and none of them have been a commercial success. This is largely due to the accumulation of losses between the raw fuel energy and the net energy

Table 2: Efficiency limiters for fuel cell systems.

\begin{tabular}{||l|r|r|r|}
\hline & Low End & High End & Mean \\
\hline Fuel Utilization or Pre-Processing Efficiency & $20.0 \%$ & $100.0 \%$ & $60.0 \%$ \\
\hline Core Fuel Cell Efficiency & $25.0 \%$ & $65.0 \%$ & $45.0 \%$ \\
\hline System Electrical Efficiency & $50.0 \%$ & $85.0 \%$ & $67.5 \%$ \\
\hline Fuel Volume Percentage of Total System & $5.0 \%$ & $50.0 \%$ & $27.5 \%$ \\
\hline \hline Net Energy Density Delivered & $0.13 \%$ & $27.6 \%$ & $5.0 \%$ \\
\hline Heat Generated Per Watt Delivered & 39 & 0.8 & 4.5 \\
\hline
\end{tabular}




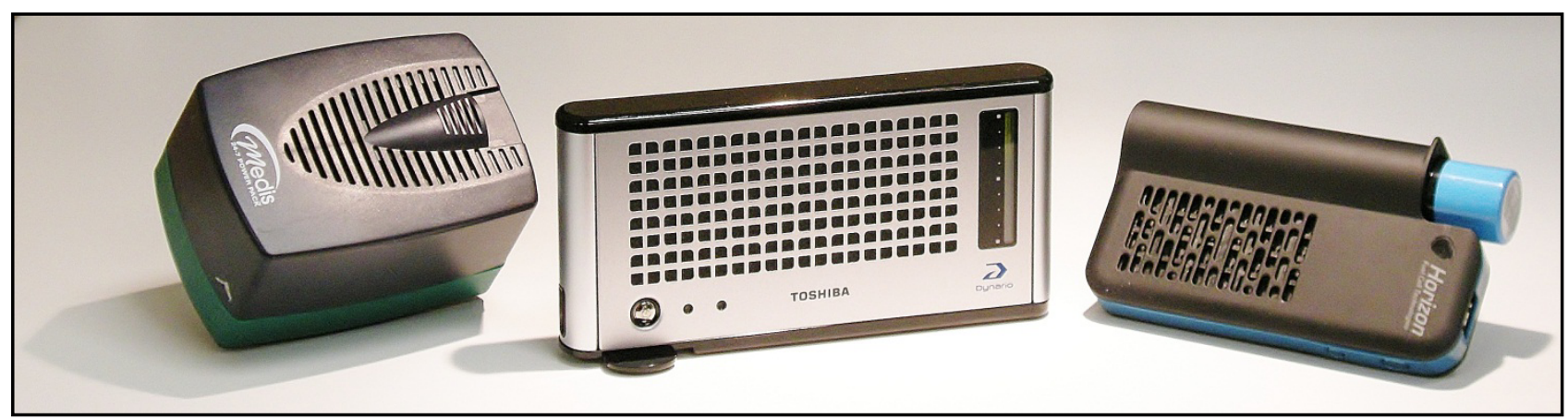

Figure 5: Images of commercially purchased fuel cells designed for portable electronics Left to right: Medis 24-7 Power Pack, Toshiba Dynario, and Horizon MiniPAK.

delivered to the user. Each system and each fuel cell is a little different, but the losses broadly fall into the four categories shown in Table 2. Even in the very best case across the board, the energy delivered is almost 4x lower than the starting fuel energy. In practice, each approach tends to excel in some areas and lag in others. In the "mean" case, the losses are 20x. As a specific recent example, the Toshiba Dynario DMFC, shown in Figure 5, delivered approximately $12 \mathrm{~W}-\mathrm{Hr}$ from a freshly filled tank in our best case testing, from a system volume of approximately $235 \mathrm{~cm}^{3}$, for a net energy density of $51 \mathrm{~W}-\mathrm{Hr} / \mathrm{L}$, or roughly $1 \%$ of the starting fuel energy density, and less energy than a comparable battery-based system. With these challenges, and the limited performance delivered, it is not surprising that fuel cells have been unable to deliver on their promise.

\section{LILLIPUTIAN KEY TECHNOLOGY CHOICES}

Lilliputian chose to pursue the highest energy density fuels, combined with the highest possible system efficiencies, in the smallest possible size, in order to deliver a complete system that dramatically beats a battery, even after all of the real-world losses are included. This required the challenging choices of butane as a fuel, SOFC as a fuel cell, and MEMS manufacturing techniques to adapt the system to small portable applications.

\subsection{Butane Fuel Selected for Safety and High Energy Density}

Butane was selected as the primary fuel because of its high energy density $(\sim 7,400 \mathrm{~W}-\mathrm{Hr} / \mathrm{L})$ and impressive safety record built up over almost one hundred years of widespread consumer use in lighters, cooking, lighting, and various specialized applications. The safety record is so strong that most spray cans for cosmetics and other products have moved to using butane as a propellant instead of the ozone depleting CFCs previously employed. ${ }^{[9]}$ These fuels are safe in large part because they are difficult to ignite. Butane's autoignition point is approximately $405{ }^{\circ} \mathrm{C}$, higher even than untreated wood ${ }^{[10]}$. The tradeoff for that safety is the need to operate at temperatures well in excess of $400{ }^{\circ} \mathrm{C}$, generally
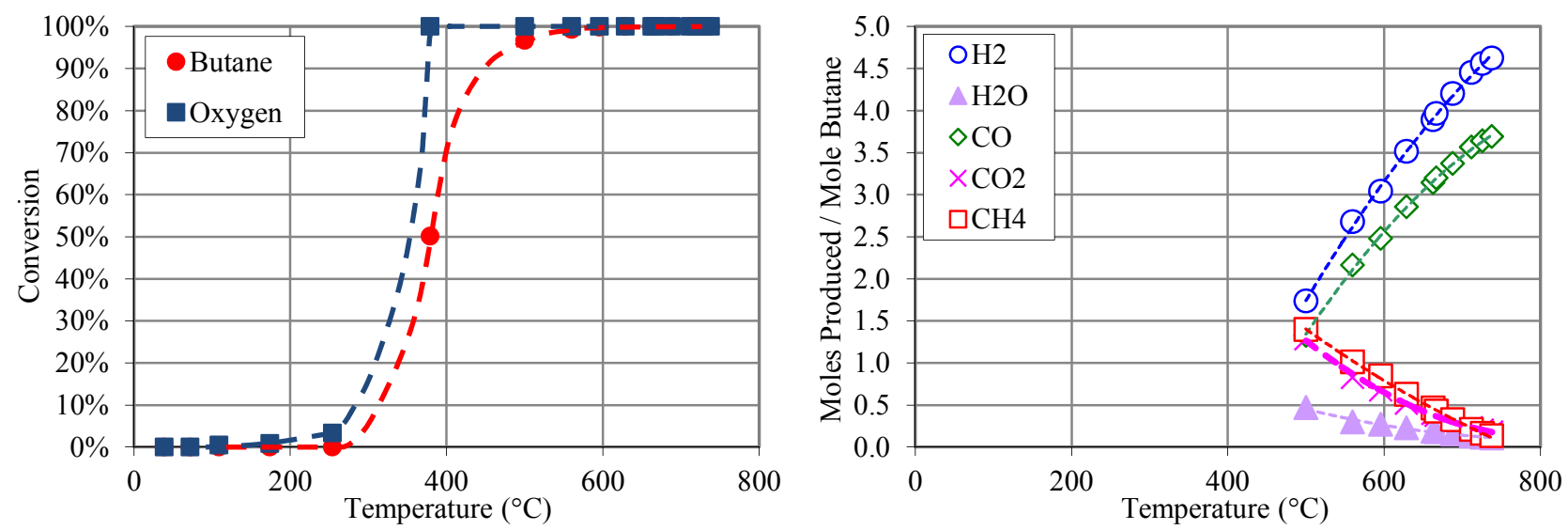

Figure 6: (Left) Fuel and oxygen conversion during the partial oxidation of butane as a function of operating temperature. (Right) Products produced as a function of operating temperature.

Reaction Conditions: $\mathrm{P}=1.1 \mathrm{~atm}, \mathrm{SV}=112,500 \mathrm{~cm}^{3} /$ h-gcat, $\mathrm{C}_{4} \mathrm{H}_{10}: \mathrm{O}_{2}: \mathrm{N}_{2}=1.0: 2.4: 9.1$. 


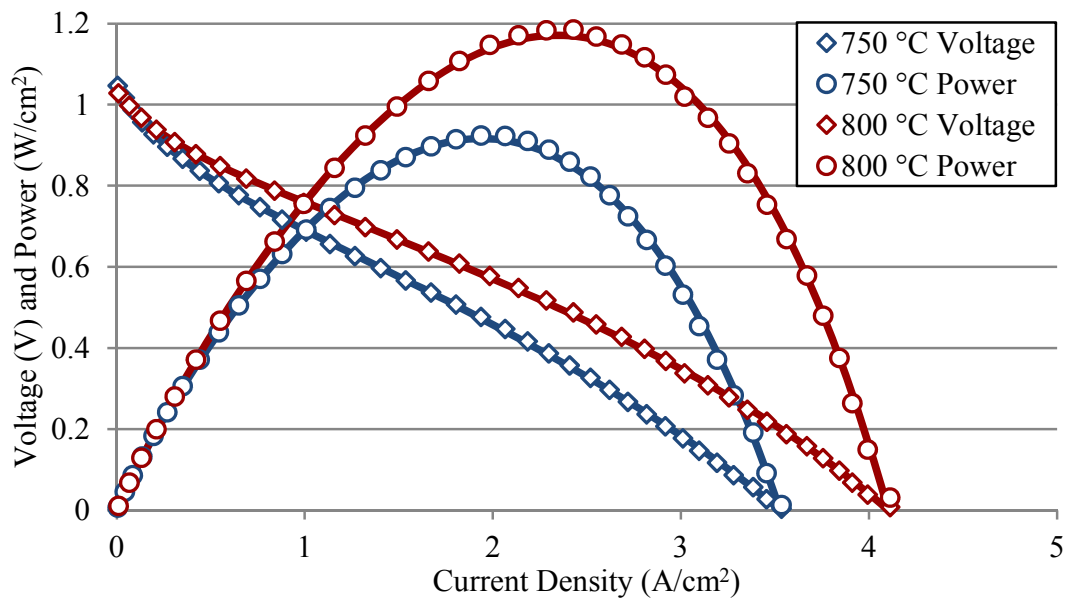

Figure 7: Voltage and Power characteristics of an early Lilliputian fuel cell.

at least $600{ }^{\circ} \mathrm{C}$ and higher. Figure 6 shows the conversion of butane in an early Lilliputian fuel reformer. Below $400{ }^{\circ} \mathrm{C}$, very little conversion occurs, but by $600{ }^{\circ} \mathrm{C}$ the conversion is essentially complete, with continued change to the product mixture at higher temperatures.

\subsection{Solid Oxide Fuel Cell Selected for Efficiency, Simple Construction, and Robustness to Environmental Factors}

Lilliputian began with a broad survey of the various fuel cell types developed over the previous 160 years, and concluded that SOFCs provided fuel flexibility, the simplest manufacturing due to its solid state construction, the best resilience to environmental contamination and humidity, and very high efficiency due to high fuel utilization and high power densities. SOFCs are defined by their use of a ceramic oxide solid as their electrolyte membrane, typically Yttrium-Stabilized Zirconia (YSZ). Sandwiched around the YSZ electrolyte are two electrodes which perform the various electrochemical reactions to complete the circuit.

$$
\begin{aligned}
& E=-\frac{\Delta G}{2 F}-\frac{R T}{2 F} \ln \left[\frac{\left(P_{O_{2}}^{\text {cathode }}\right)^{\frac{1}{2}} P_{H_{2}}^{\text {anode }}}{P_{\mathrm{H}_{2} \mathrm{O} \text { Ode }}}\right] \\
& \Delta G \equiv \text { Gibbs Free Energy } \\
& F \equiv \text { Faraday Constant } \\
& R \equiv \text { Gas Constant } \\
& P_{\mathrm{O}_{2}}^{\text {cathode }} \equiv \text { Partial pressure of } \mathrm{O}_{2} \text { at Cathode } \\
& P_{\mathrm{H}_{2}}^{\text {anode }} \equiv \text { Partial pressure of } \mathrm{H}_{2} \text { at Anode } \\
& P_{\mathrm{H}_{2} \mathrm{O}}^{\text {ande }} \equiv \text { Partial pressure of } \mathrm{H}_{2} \mathrm{O} \text { at Anode } \\
& P_{\mathrm{O}_{2}}^{\text {cathode }}=0.2 \quad P_{\mathrm{H}_{2}}^{\text {anode }}=0.4 \quad P_{\mathrm{H}_{2} \mathrm{O}}^{\text {anode }}=0.03 \rightarrow E=-0.99-0.08 \mathrm{~V}=-1.07 \mathrm{~V}
\end{aligned}
$$

When no current is flowing, known as the Open Circuit Voltage (OCV) condition, no reactions occur at either electrode, and no current flows within the electrolyte, and so the voltage produced matches the theoretical voltage found from the Nernst equation (1) quite closely in well-built SOFCs. A typical OCV condition is shown in (2). However, as current is allowed to flow through a load, losses develop at multiple points in the electrochemical circuit. The simplest loss comes from the resistance of the electrolyte. Generally more significant are the polarization losses that develop as the electrodes are required to quickly execute on the reactions to deliver new ions and electrons into the circuit, which in turn causes linear and non-linear voltage losses. Finally, if sufficient current flows that either oxygen or fuel is unable to diffuse to the active regions of the electrode as fast as it is removed, the SOFC is said to be mass transport limited, and the concentration terms in the Nernst equation quickly drop, causing a "knee" in the curve as the voltage drops off more rapidly. Put together, an ideal SOFC curve looks like the one shown in Figure 7 from an early Lilliputian SOFC test structure. Maximum power is generally produced between 0.4 and 0.7 Volts, depending on the fuel cell and operating environment.

The most critical figure of merit for a fuel cell is the maximum power density that it can produce. In order to improve that value for a given fuel cell, there is little choice but to operate at a higher temperature. To produce a fuel cell which delivers more power at any given temperature, the electrode performance must be improved by increasing the density of active electrode sites and/or using more catalytically active materials, and the electrolyte resistance must be minimized by either reducing the thickness and/or using more conductive materials. 


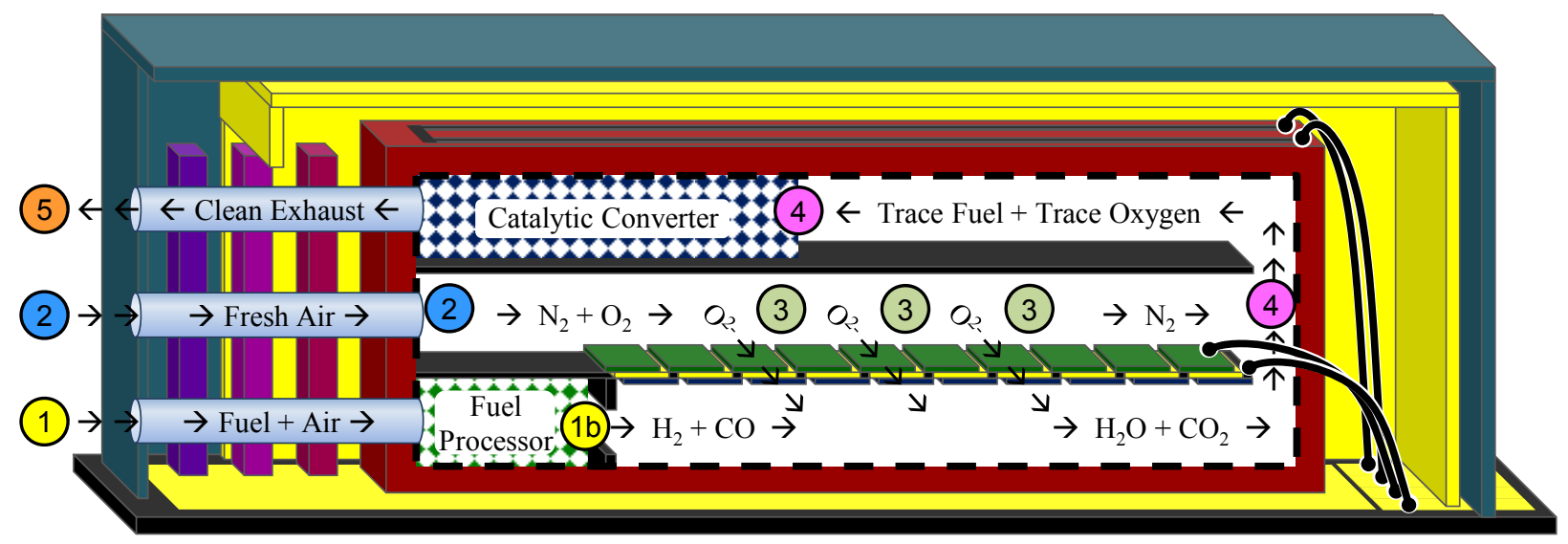

Figure 8: Schematic of Lilliputian's Generator Chip: (1) Fuel is mixed with a small amount of Air and fed into the Fuel Processor, (1b) Fuel breaks down into simpler fuels, Hydrogen $\left(\mathrm{H}_{2}\right)$ and Carbon Monoxide (CO), which are easier for the Fuel Cell to use, (2) Air is provided to the other side of the Fuel Cell, (3) Fuel and Air react across the Fuel Cell membrane, producing Electrical Power at the terminals of the Fuel Cell, (4) Remaining Fuel mixes with Remaining Air and is burned and cleaned in the Catalytic Converter, (5) Clean Exhaust leaves the Generator Chip.

\subsection{MEMS Manufacturing Selected for Complex Mechanical Construction and Compact Size}

Butane and SOFCs are both selections that require operation at temperatures of at least $500{ }^{\circ} \mathrm{C}$, and up to $1000{ }^{\circ} \mathrm{C}$. Delivering those temperatures at low power levels and in a small package requires extreme levels of insulation and very tight integration of all components. Insulation and heat-recovery of the gas flows required is particularly challenging. Previous work at MIT developed a manufacturing approach to build thin-walled tubes with excellent insulation and heat recovery using silicon $\mathrm{MEMS}^{[11]}$; advancements on that work are shown in Figure 9.

Most SOFCs are built as self-supporting ceramic assemblies, or built using ceramic substrates. However two major factors drove our need to integrate the SOFC onto a silicon substrate. First, the thermal cycling required would drive significant thermal expansion stresses if dissimilar materials were used as substrates, and the tube structure had previously been developed on silicon. Second, the very tight integration required drives the need for tightly packed structures, which can most easily be formed using existing silicon-based photolithograph and etch processes. Early work at Lawrence Livermore National Laboratory (LLNL) pioneered the use of fuel cells integrated onto silicon substrates ${ }^{[12]}$, and Lilliputian has continued to build on that early work.

Outside of the heat recuperator and the SOFC, the remaining high-temperature components are a fuel processor and a catalytic converter (a.k.a. tail gas burner), both of which are formed from catalyst coatings on much simpler silicon flow passages. Here MEMS also shines from the use of very simple bulk etched structures. Applied to all of the required components, MEMS delivers the intended structures into high-volume manufacturing and in a very small form factor.

\section{INTEGRATION CHALLENGES}

Having chosen the three key design elements of butane, SOFC and silicon MEMS, the real challenges begin with integration of all of the required components. In order to build a compact, fully insulated and functional "Generator Chip", shown in Figure 8, the following demands needed to be addressed:

- Integrated extreme insulation with Tubes/Heat Exchanger, Vacuum, Radiation Shielding, and Wire Losses

- Hermetic sealing together of multiple silicon-based components

- Integration of SOFC materials with the silicon substrate and overcoming the significant CTE mismatch

- Integration of fuel cell stacking in-plane

- Optimizing fuel and air flow distributions for maximum fuel utilization

\subsection{Insulated Generator Chip}

Delivering 2-3 Watts of electricity to a consumer electronics load at efficiencies of at least $25 \%$ requires that the losses be no larger than 6-9 Watts combined. This is clearly a tall challenge for a $600-1000{ }^{\circ} \mathrm{C}$ chemical plant. The primary 

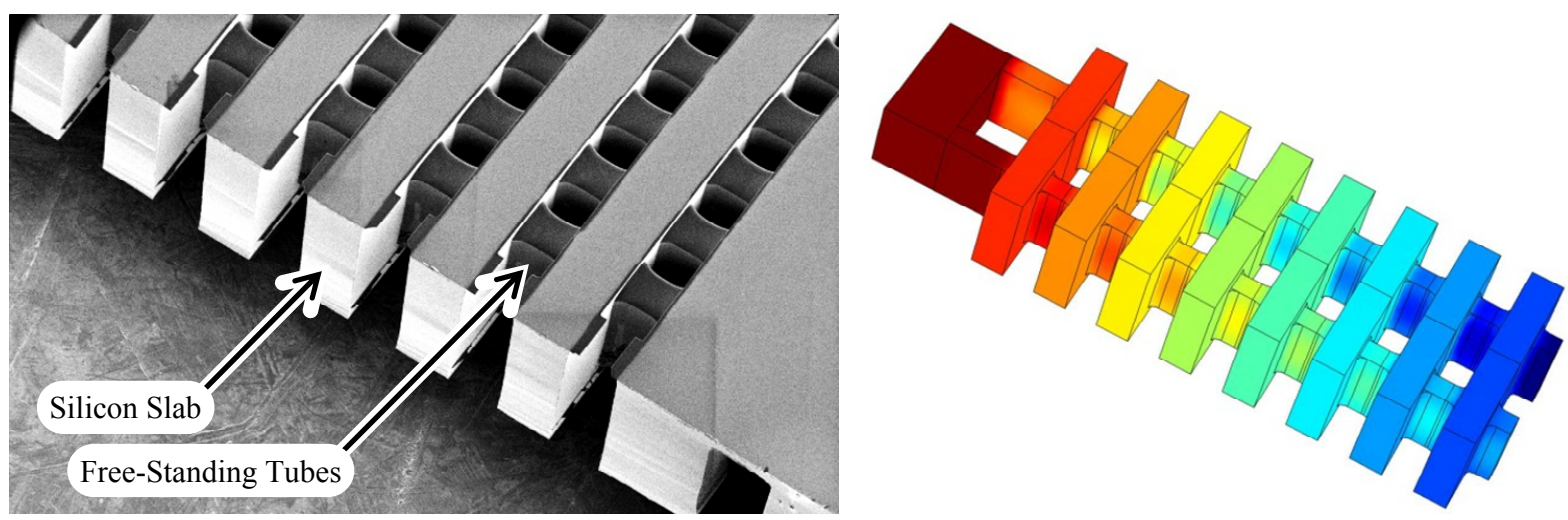

Figure 9: (Left) Electron-micrograph of MEMS Tubes, (Right) Modeling of heat recovery characteristics.

thermal loss pathways are conduction through any insulation, infrared radiation, conduction through tubing and wiring, and forced convection of hot exhaust gasses.

The most compact form of insulation is vacuum because the direct conduction losses can be made arbitrarily small by suitably rarefied vacuum levels. For our application, vacuum levels under 1 millitorr essentially eliminate the first thermal loss pathway. This choice does require the development of thermally-stable and vacuum-tight sealing materials, discussed in the next subsection, however there is little choice; even aerogel insulation would need to be unacceptably large to meet the required heat loss.

Without physical conduction, the radiation of infrared light, if allowed to escape, would still cause up to 200 Watts of heat loss from our compact Generator Chip. To minimize this pathway, highly reflective shields surround the hot region as completely as possible; only the tube structure is allowed to pierce the shielding. Even with this approach, light that escapes through gaps for the tubes and wire traces dominate the remaining heat loss.

The heated region can be suspended in vacuum, and surrounded with reflectors, but it must still have tubing to provide gasses and remove exhaust, and it must have wires to extract the power produced and provide power to the startup heater. Those physical contacts must be designed to have minimal heat loss. Wire losses are minimized by using smalldiameter wire; however, the thermal resistance and electrical resistance are governed by the same geometric factors. The high thermal resistance wires are, by definition, also high electrical resistance. In order to extract the electrical energy from the SOFC through high-resistance wires, the voltage must be increased significantly to reduce the current and associated resistive losses. In-plane stacking, discussed in a later section, is used to boost the voltage without increasing the overall Generator Chip size.

Convective heat loss from the required gas flows contains less energy than the preceding mechanisms, but it is also one of the most challenging pathways to eliminate. The MEMS tubes, shown in Figure 9, provide gas flow with very little physical conduction by using very thin-walled tubes of insulating silicon nitride. Silicon heat transfer bars are provided perpendicular to the tubes to provide very efficient recovery of the heat from the exhaust stream back into the input gas

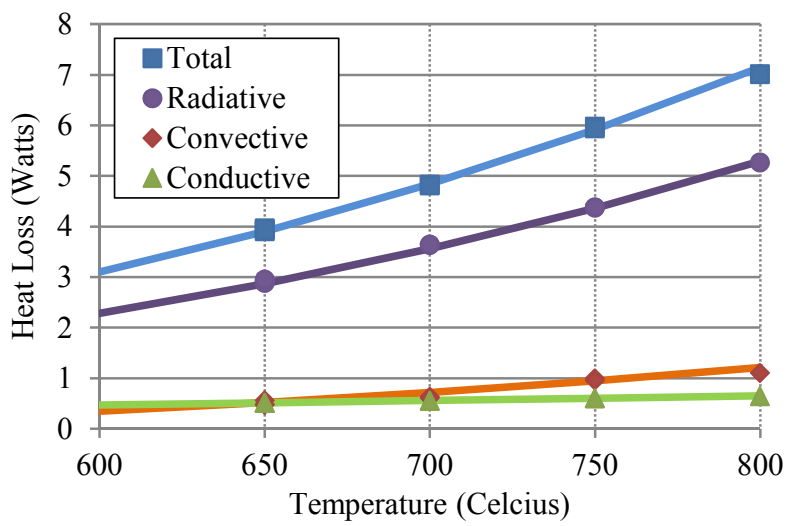

Figure 10: Extreme insulation measured on a representative Generator Chip. 


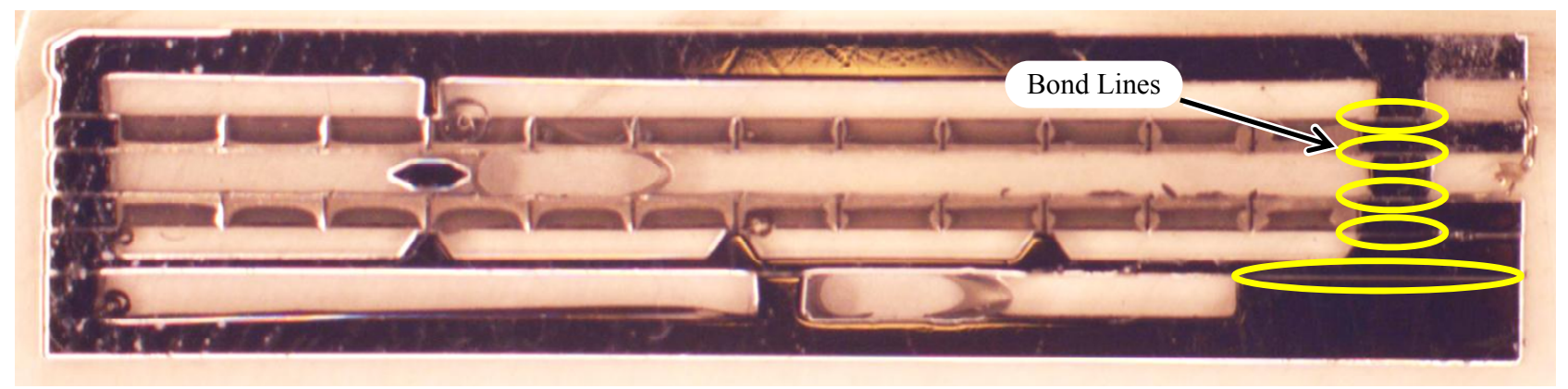

Figure 11: Cross section of an assembled silicon die stack using Lilliputian's glass seal.

streams. Arbitrarily high levels of recovery could be provided with very small tubes, but at the cost of very high pressure drop. Any increase in pressure drop reduces system efficiency because more energy is wasted in the air pumping system. Alternatively, large numbers of small parallel tubes would also increase heat recovery without increased pressure drop; however, the larger X-sectional area would increase radiation and conduction heat loss, swamping any benefit. Lilliputian has selected an intermediate point, but the losses from this pathway are still the $2^{\text {nd }}$ largest overall.

Combined, the losses from this suite of extreme insulation approaches result in approximately 3-7 Watts of heat loss over the temperature range of interest for our system, as shown in Figure 10. This matches well with the heat generated from the SOFC and the catalytic reactions, creating an autothermal system.

\subsection{High-Temperature, Vacuum-Tight Sealing Glass}

Vacuum insulation has tremendous advantages, as mentioned previously, but requires truly hermetic sealing between the multiple silicon components that comprise the Generator Chip in order to maintain the vacuum level over the life of the device. The use of silicon as the primary structural material throughout the Generator Chip limits the stress on the seal, but that seal is still subject to a very challenging set of requirements:

- Operation at temperatures up to $800-1000^{\circ} \mathrm{C}$ with frequent thermal cycling

- Stability in highly oxidizing environments (air)

- Stability in highly reducing environments (reformate)

- High strength (ability to withstand $\sim 1$ atmosphere internal pressure)

- Near perfect thermal expansion match to silicon

Traditional wafer bonding technologies such as silicon fusion bonding would meet these requirements, but they require extremely clean and flat surfaces. Unfortunately, fuel cell manufacturing requires extensive processing to create the electrode, and there are numerous electrical interconnects that cross bond lines. Producing sufficiently high yield with conventional bonding would be very challenging. Glass seals are a more natural technology fit, but no commercially

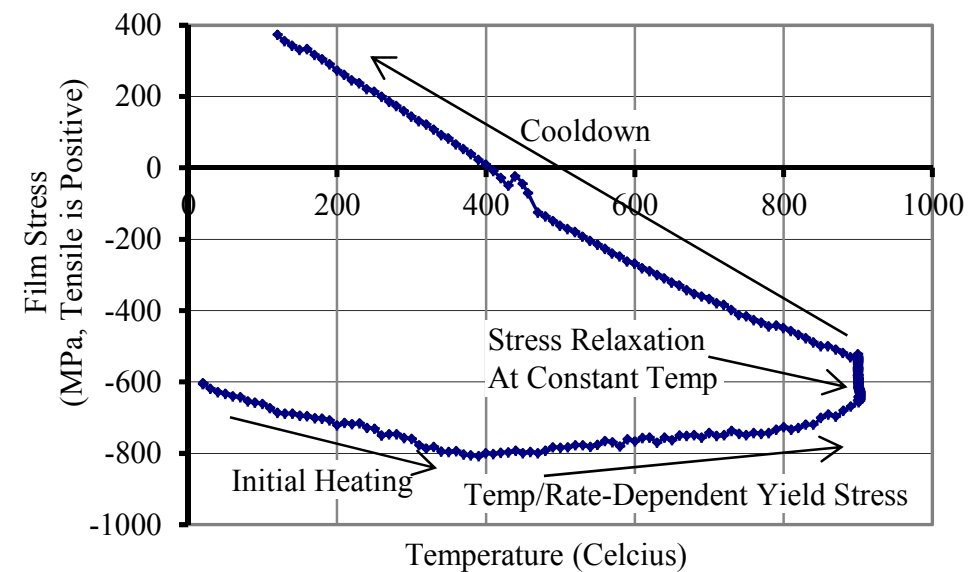

Figure 12: Stress vs. Temperature during the first thermal cycle of an example YSZ film. Film thickness of $2 \mu \mathrm{m}$, heating and cooling rates of $6^{\circ} \mathrm{C} /$ minute, dwell time of 3 hours. 

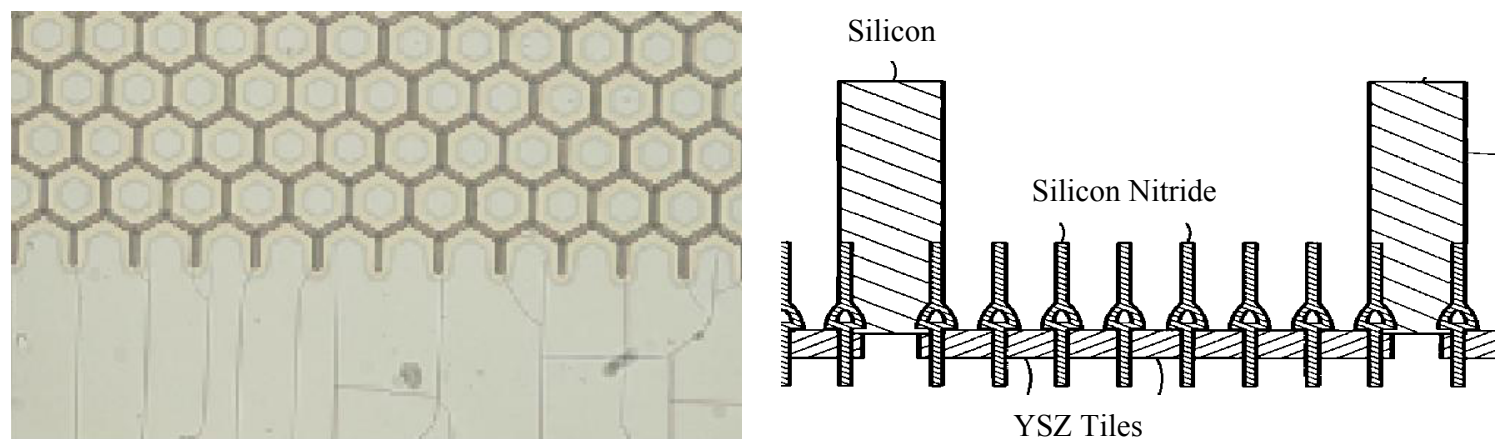

Figure 13: (Left) Micrograph of the edge of a Pre-Cracked region, and (Right) Cross-sectional diagram.

available sealing material was identified which met all of the aforementioned requirements. Therefore, Lilliputian developed a novel sealing glass which is able to provide the required characteristics at very high yields. Figure 11 shows a cross-section from a six-die stack assembled with this glass.

\subsection{SOFC on Silicon Thermal Expansion Mismatch}

Early work at LLNL demonstrated SOFCs fabricated on a silicon substrate ${ }^{[13]}$, but the large thermal expansion mismatch between the silicon and the YSZ electrolyte caused the membranes to fail after thermal cycling. Between 0 and $900{ }^{\circ} \mathrm{C}$, over $1 \mathrm{GPa}$ of stress is developed in a YSZ film deposited on silicon. Shown in Figure 12 is the first thermal cycle of a YSZ film deposited on a silicon wafer. Initially the stress is $400 \mathrm{MPa}$ compressive. As the wafer heats up, the film becomes more compressive until it exceeds the yield stress. Despite being a crystalline ceramic, the stress levels are high enough to induce plastic deformation in the film between 400 and $900{ }^{\circ} \mathrm{C}$, as well as some additional stress relaxation at $900{ }^{\circ} \mathrm{C}$. During the subsequent cool down, the thermal expansion mismatch drives the previously highly compressive stress in the film all the way to a highly tensile state, ultimately resulting in significant fracturing in the film.

Cracking in a fuel cell is fatal because it allows gas to bypass the electrochemical circuit and simply combust through the membrane directly. To prevent this, Lilliputian invented a "Pre-Cracked" structure where the YSZ film is constructed with closely spaced seams prior to thermal cycling, with seals under each seam. Figure 13 shows the edge of a PreCracked region. Outside of the patterned area, numerous cracks are clearly visible, but within the "Pre-Cracked" area, no unintentional cracks form.

The Pre-Cracked structure is completed by removing the underlying silicon to form a free-standing composite membrane. The small YSZ "tiles" are supported on a silicon nitride lattice, which is supported in turn by silicon walls to form YSZ/nitride composite "membranes". The membranes can then be replicated in a large array to cover arbitrarily large surface areas. In this way even 1,000,000 crack-free tiles can be readily combined onto one silicon die.

\subsection{In-Plane Electrical Stacking}

Small wires required for minimizing heat loss require that the fuel cell generate many volts to avoid excessive electrical losses. Large-scale fuel cells typically address this issue by physically stacking multiple fuel cells into a tower, such that the anode of one cell is adjacent to the cathode of the next cell, thereby connecting them in series and adding up the voltages. For example, with operating voltages of $<0.7 \mathrm{~V}$, generating 10 Volts would require at least 15 cell stacks. Even if the stacks could be formed with $1 \mathrm{~mm}$ per layer, that would require at least $15 \mathrm{~mm}$ in height just for the fuel cell stack, not including insulation or packaging, which is problematic for portable applications. Further, with high power density electrodes $>1$ Watt per $\mathrm{cm}^{2}$, each layer would only be a few $\mathrm{mm}$ on each side, leading to enormous waste in perimeter overhead.

To avoid this awkward stack, Lilliputian developed an in-plane electrical stacking architecture. Taking advantage of the patterning capabilities of MEMS, each fuel cell layer is segmented into multiple disconnected cells. Those cells are then wired in series using vias through the electrolyte to multiply the voltage to the required level. Shown in Figure 14 is a small section of three sequential cells connected anode-to-cathode.

One of the key steps in constructing the in-plane stack is formation of the via. Because the via spans both the reducing anode cavity and the oxidizing cathode cavity, it is critical that it is gas tight, stable in both environments, and maintains its electrical conductivity in both environments. One solution developed at Lilliputian for this challenge is the use of a 

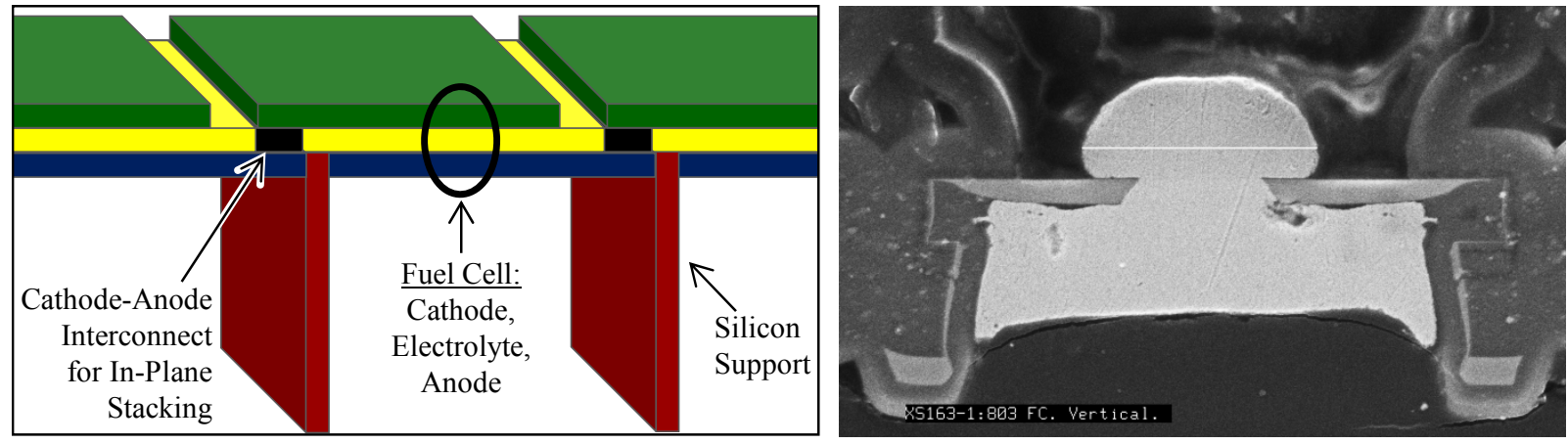

Figure 14: (Left) Diagram of in-plane electrical stacking of multiple fuel cells. (Right) Electron-micrograph of a crosssection of the interconnect via.

"rivet" shaped plug built through the YSZ tile described above (Figure 14). The rivet shape is chosen to ensure that any high-temperature restructuring of the plug does not result in leakage.

\subsection{Fuel and Air Distribution for Maximum Utilization}

Maximum efficiency of the fuel cell system depends on balancing two competing goals: To maximize the core fuel cell efficiency, the fuel and oxygen concentrations should be kept as high as possible over the entire fuel cell surface. However, to maximize fuel conversion efficiency, you should consume as much fuel in the fuel cell as possible to minimize losses, and consume as much of the oxygen as possible to minimize wasted pump energy. Lilliputian developed a multi-physics model, which combines a local fuel cell electrical model, properly accounts for the in-plane stacking, and includes gas-phase flow and diffusion of all relevant reactants.

Figure 15 shows the computational results of this optimization, as well as some experimental data which validates this approach. By improving the flow distribution, we are able to delay the onset of mass transport effects to approximately $50 \%$ higher current levels. This directly translates to more electrical power produced for a given fuel flow, and therefore higher efficiency.

\section{COMPLETE SYSTEM}

Lilliputian's Generator Chip contains tremendous technology innovations, many of which were covered above, but it is useless to a consumer without a system surrounding it. Much like the engine block of a car, which performs a similar fuel-to-work conversion, it is surrounded by a far larger volume of auxiliary "Balance of Plant" (BoP) components which deliver the desired user experience.
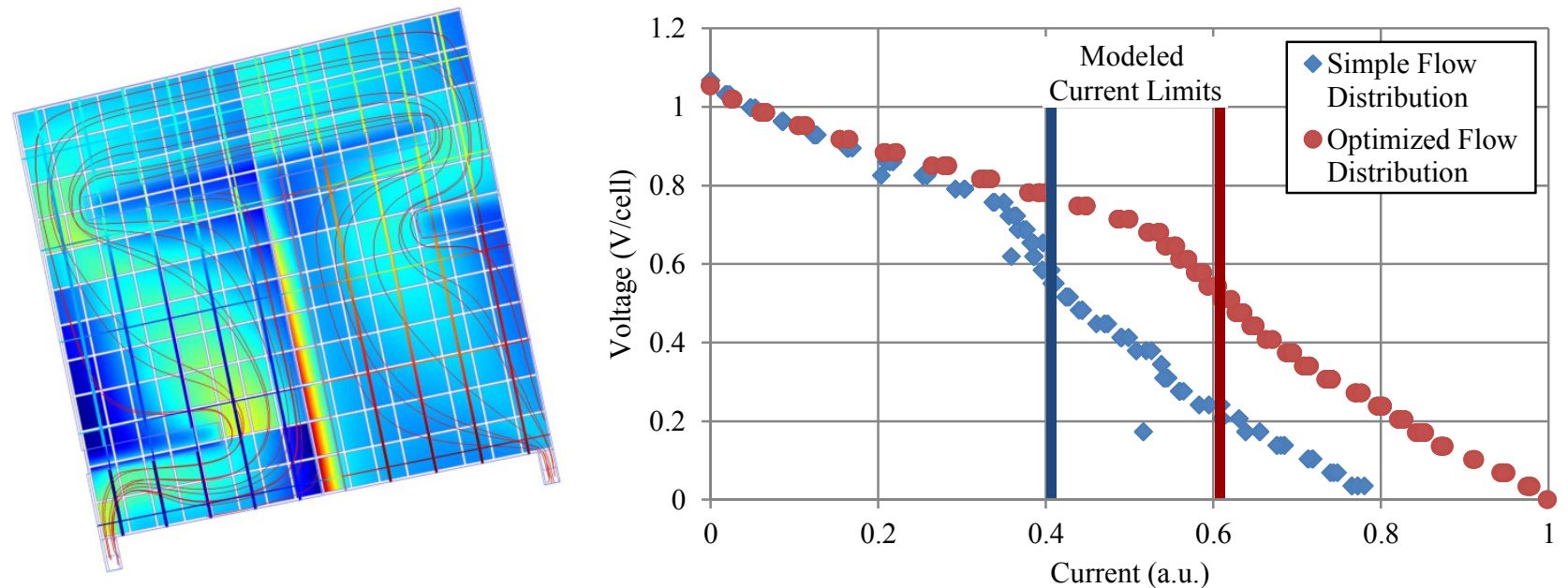

Figure 15: (Left) Multiphysics model of current distribution over the fuel cell surface, (Right) Electrical characterization of two fuel cells with simple vs. optimized flow distributions. 


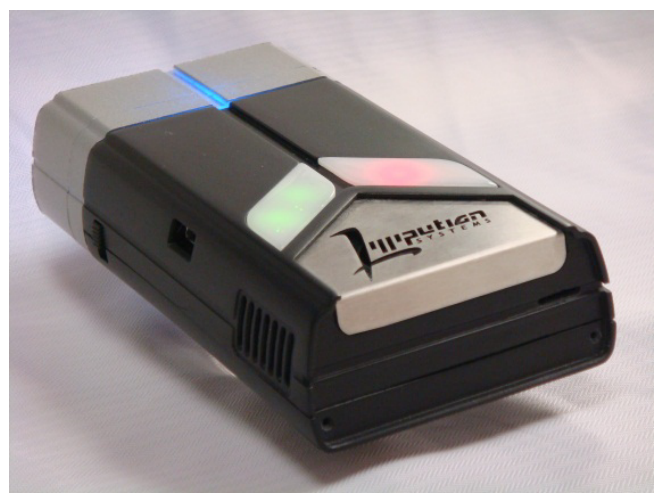

Figure 16: Prototype Lilliputian complete system.

\subsection{Pumps, Valves and Electronics}

At a minimum, the BoP must provide the Generator Chip with three gas input streams (fuel, air for reforming, and air for the SOFC cathode), one electrical startup heater, one temperature measurement, and one fuel cell output power converter. In the Lilliputian system, those needs are met with an air pump which supplies both air streams, a fuel valve which meters fuel out of the pressurized butane cartridge, and a number of DC/DC converters to shuttle power around the system. Consistent temperature is maintained by adjusting the fuel flow as needed using a fuel valve. All of these operations are managed by a sophisticated embedded controller. Shown in Figure 17 is the high-level system design for a small portable butane SOFC system. ${ }^{8}$

Unfortunately, all of these BoP components consume electrical power, and therefore require that the Generator Chip produces "extra," wasting additional fuel and generating additional heat. Meticulous design of the electronics, within cost constraints, minimizes the converter losses. Air pump power is minimized by using high efficiency pump designs, but more powerfully by minimizing the pressure drop of the system. Every flow path and mixing region of the system has been modeled and optimized for minimal pressure drop.

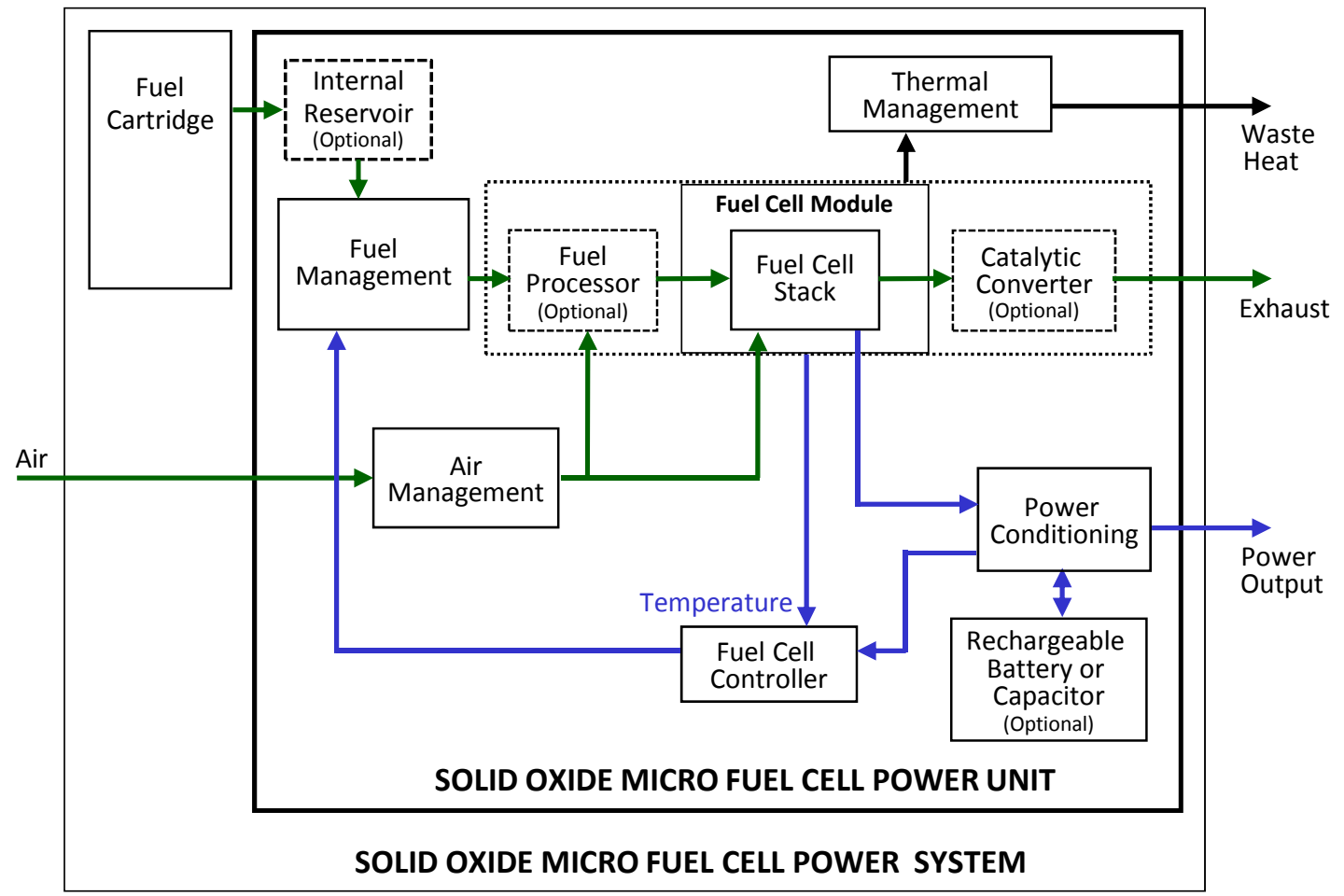

Figure 17: Butane Fuel Cell System block diagram. ${ }^{8}$ 


\subsection{User Experience}

Consumers need a device which is compact and high-energy that they can use as if it were a portable wall outlet, with little regard to the internal workings of the system and Generator Chip described above. The system should deliver power immediately, and deliver as much power as the device can accept, or as little as it needs. The most straightforward way to provide that user experience is to include a rechargeable battery within the system which is able to deliver instant power and peak power as needed. The rest of the fuel cell system is essentially configured to recharge that internal battery. Figure 18 shows the basic state machine. A typical operational sequence for Lilliputian's system is as follows:

1. User attaches a device to the USB Port.

2. Power is available immediately from the system's internal rechargeable battery.

3. If the user's device requires high power levels, or if the system's internal battery is low, the system automatically starts the Generator Chip.

4. During Generator Chip startup, which takes a few minutes, power continues to be supplied to the USB Port from the system's internal battery.

5. When the Generator Chip is running, the power from the Fuel Cell provides power to the USB Port as well as recharges the system's internal battery.

6. If the user's device no longer requires full power levels, and when the MPS battery has been fully recharged, the system automatically shuts off the Generator Chip.

7. Power continues to be supplied, as needed, to the USB Port by the system's internal battery

If the fuel tank is empty or removed:

1. Power continues to be supplied to the USB Port until the system's internal battery is at a minimum reserve.

2. If the Generator Chip was running, it is stopped.

3. When a new tank is attached, the Generator Chip is started, as necessary.

\section{CONCLUSION}

Portable fuel cells can cut the final cord connecting consumer electronics users to the wall, at a time when people are increasingly dependent on their amazing devices, and increasingly frustrated by the frequent pull back to a non-mobile plug. Relentless pursuit of the highest performance choices in the form of butane fuel, SOFC fuel cells and MEMS combine to provide a technology basis capable of finally delivering on the fuel cell promise; however, those choices come with complications. Integration of the core Generator Chip required solving complex insulation challenges, developing a new sealing approach, leveraging microfabrication into ceramic fuel cell materials, and optimizing intricately coupled flow, reaction and electrical distributions. Even after surmounting these integration barriers, the Generator Chip had to be incorporated into a full system to deliver the required user experience reliably and at a competitive price.

Over the past several years, Lilliputian Systems has created the many innovations required to bring this complex system to high-volume manufacturing, and ultimately to the mobile world, enabling Lilliputian to provide long-lasting portable power for consumer electronics devices.

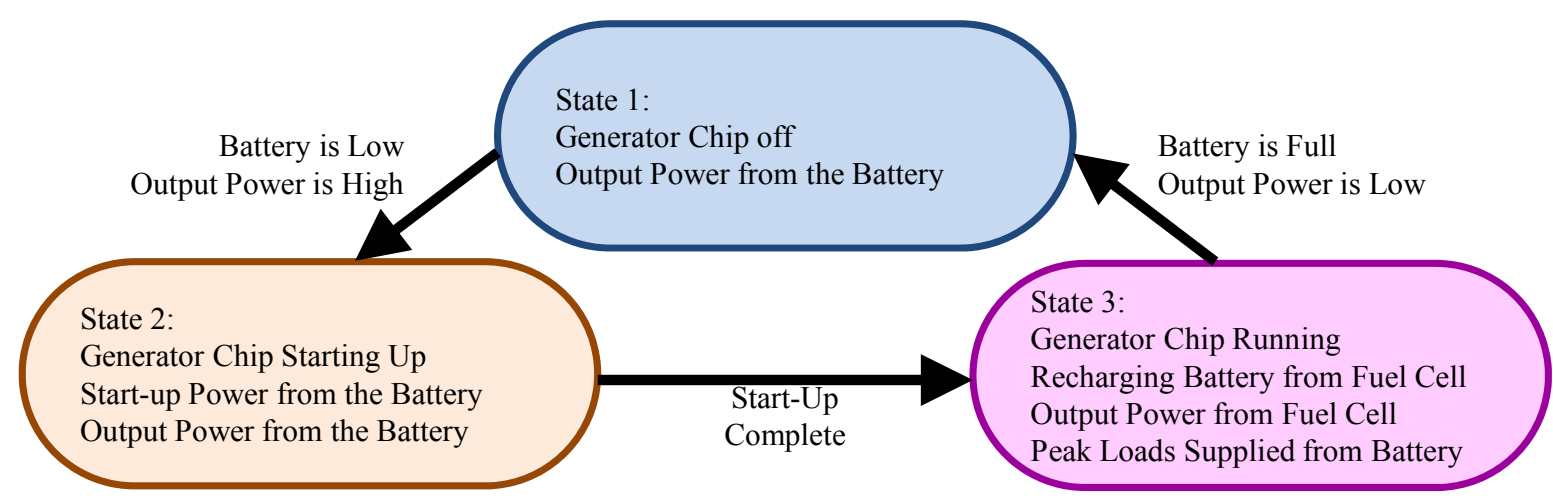

Figure 18: System operational state loop. 


\section{REFERENCES}

[1] Wolfe, A., "Is The Smartphone Your Next Computer?", InformationWeek Dec. 2008, InformationWeek, San Francisco, (2008)

[2] Wang, H., Jiang, Y. and Philips, L., [Mobile Convergence: Platform, Applications \& Services], Parks Associates, Dallas, (2009)

[3] Robinson, S., [Cellphone Energy Gap: Desperately Seeking Solutions], Strategic Analytics, Newton \& Militon Keynes, 1-28 (2009).

[4] Mawston, N., [Global Handset Sales Foresast by Country: 2002 to 2014], Strategic Analytics, Newton \& Militon Keynes, (2009).

[5] Spektor, A., Joy, B., Kang, Tom., Mawston, N., [Global Handset Revenues, ASPs \& Price-Tiers: 2003 to 2004], Strategic Analytics, Newton \& Militon Keynes, (2009).

[6] Cisco Systems, [Cisco Visual Networking Index: Global Mobile Data Traffic Forecast Update, 2010-2015], Cisco Systems, San Jose, (2011)

[7] National Research Council, [Energy-Efficient Technologies for the Dismounted Soldier], The National Academies Press, Washington, DC, (1997).

[8] International Electrotechnical Commission, [IEC 62282-6-100 Fuel cell technologies - Part 6-100: Micro fuel cell power systems - Safety, Edition 1.0], IEC, Geneva, (2010).

[9] Nardini, G., [Aerosol Sector Conversion in Action], OzonAction Information Clearinghouse, Paris, (1995)

[10] U.S. Forest Products Laboratory, [Ignition and Charring Temperatures of Wood], U.S Forest Service, Madison, Wisconsin, (1958)

[11] Arana, L. R., Schaevitz, S. B., Franz, J. F., Schmidt, M. A. and Jensen, K. F., “A Microfabricated Suspended-Tube Chemical Reactor for Thermally Efficient Fuel Processing," J. MEMS 12(5). 600-612 (2003).

[12] Morse, J. D., Jankowski, A. F., "A Novel Thin Film Solid Oxide Fuel Cell for Microscale Energy Conversion," Proc. SPIE 3876, 223-226 (1999).

[13] Jankowski, A. F., Graff, R. T., Hayes, J. P., Morse, J. D., "Testing of Solid Oxide Fuel Cells for Micro to Macro Power Generation," Solid Oxide Fuel Cells (SOFC VI), 932-937 (1999). 